\title{
Improved Method for the Determination of Tobacco-specific Nitrosamines (TSNA) in Tobacco Smoke *
}

\author{
by Sopbia Fischer and Bertold Spiegelhalder \\ Institute of Toxicology and Chemotherapy; German Cancer Research Center, \\ Heidelberg Federal Republic of Germany
}

Dedicated to Prof. Dr. R. Preussmann on the occasion of his 60th birthday.

\section{SUMMARY}

The method used to determine tobacco-specific nitrosamines [TSNA], $N^{3}$-nitrosonornicotine [NNN], 4-(methylnitrosamino)-1-(3-pyridyl)-1-butanone [NNK], $N^{\prime}$-nitrosoanabasine [NAB] and $N^{*}$-nitrosoanatabine [NAT], in mainstream smoke was modified. The methodology included trapping mainstream smoke in a buffer solution and on a Cambridge filter, extracting TSNA from the buffer solution and the filter with dichloromethane, clean-up procedures and analysis by GC/TEA. Extracts from both the buffer solution and the filter were cleaned up and analyzed individually. The clean-up procedure included column chromatography on basic alumina and the removal of nicotine. $N$-Nitrosodibenzylamine [NDBenzA] which had suitable chromatographic properties was used as internal standard. $N^{3}$ Nitrosopentylpicolylamine [NPePicA], a newly synthesized nitrosamine with physicochemical properties similar to the TSNA, could also be used as an internal standard. The recoveries for the buffer solution were as follows: NDBenzA $89 \%$, NPePicA $83 \%$, NNN $85 \%$, NNK $88 \%$, NAB/NAT $85 \%$. For the TSNA trapped on the filter the following recoveries were determined: NDBenzA $81 \%$, NPePicA $75 \%$, NNN $77 \%$, NNK 78\%, NAB/NAT $75 \%$.

Parameters influencing the TSNA values in the mainstream smoke were investigated. Artifact formation of TSNA during mainstream smoke collection did not oc-

\footnotetext{
* Received: 29h June 1988 - accepred; 30th August 1988.
}

cur under standard conditions. TSNA values were greatly influenced by the puff volume, they increased with increasing puff volume.

Reproducible and reliable results can be achieved in a relatively short time with the method reported.

\section{ZUSAMMENFASSUNG}

Die in der Literatur beschriebene Methode zur Bestimmung tabakspezifischer Nitrosamine [TSNA], $N^{\prime}-\mathrm{Ni}-$ trosonornicotin [NNN], 4-(Methylnitrosamino)-1-(3-pyridyl)-1-butanon [NNK], $N$ 'Nitrosoanabasin [NAB] und $N^{3}$-Nitrosoanatabin [NAT], im Hauptstromrauch wurde verbessert. Das hier vorgestellte Verfahren umfaßt das Auffangen des Hauptstromrauches in einer Kombination aus Flüssigkeitsfalle mit Pufferlösung und einem Cambridge-Filter, Extraktion der TSNA aus der Pufferlösung und dem Filter mit Dichlormethan, Aufarbeitungsschritten und Analyse mittels GC/TEA. Die Extrakte von Pufferlösung und Filter wurden einzeln aufgereinigt und analysiert. Die Anreicherung der TSNA erfolgte mittels Säulenchromatographie über basisches Aluminiumoxid und Entfernung von Nicotin. $N$-Nitrosodibenzylamin [NDBenzA], das geeignete chromatographische Eigenschaften aufweist, wurde als interner Standard benutzt. N'-Nitrosopentylpicolylamin [NPePicA], ein neu synthetisiertes Nitrosamin mit physikochemischen Eigenschaften, welche mit denen der TSNA vergleichbar sind, konnte auch als in- 
terner Standard eingesetzt werden. Die Wiederfindungsraten der TSNA in der Pufferlösung waren: NDBenzA $89 \%$, NPePicA $83 \%$, NNN $85 \%$, NNK $88 \%$, NAB/NAT $85 \%$. Für den Filterextrakt wurden folgende Wiederfindungsraten ermittelt: NDBenzA $81 \%$, NPePicA $75 \%$, NNN $77 \%$, NNK $78 \%$, NAB/NAT $75 \%$.

Parameter, die die 'TSNA-Werte im Hauptstromrauch beeinflussen, wurden überprüft. Artefaktbildung von TSNA während des Auffangens des Hauptstromrauches konnte unter Standardbedingungen nicht beobachtet werden. Die TSNA-Werte wurden stark vom Zugvolumen beeinflußt, sie nahmen mit zunehmendem Zugvolumen zu.

Mit der vorgestellten Methode kōnnen reproduzierbare und verläßliche Ergebnisse mit geringem Zeitaufwand erreicht werden.

\section{RESUME}

Des améliorations ont été apportées a la méthode utilisée habituellement pour la détermination des teneurs en nitrosamines spécifiques du tabac [TSNA], $N^{\prime}$-nitrosonornicotine [NNN], 4-(méthylnitrosamino)-1-(3-pyridyl)-1-butanone [NNK], $N$ '-nitrosoanabasine [NAB] et $N$ 'nitrosoanatabine [NAT], dans le courant principal de la fumée. Dans le procédé présenté ici, le courant principal a été retenu dans un dispositif combinant un piège à liquide avec solution tampon et un filtre Cambridge, les TSNA étant extraites de la solution tampon et du filtre par le dichlorométhane. Les produits extraits respectivement de la solution tampon et du filtre ont été purifiés et analysés séparément par GC/TEA. Le traitement des TSNA a compris chromatographie sur colonne (alumine basique) et élimination de la nicotine. C'est la $N$-nitrosodibenzylamine [NDBenzA] qui a été utilisée comme étalon interne en raison de ses propriétés chromatographiques bien adaptées. Il a été

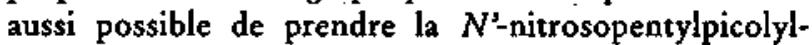
amine [NPePicA], une nouvelle nitrosamine de synthèse dont les propriétés physico-chimiques sont comparables a celles des TSNA. Les taux de récupération des TSNA dans la solution tampon ont été les suivants: NDBenzA $89 \%$, NPePicA $83 \%$, NNN $85 \%$, NNK $88 \%$, NAB/NAT $85 \%$. En ce qui concerne le produit extrait du filtre, les taux ont été : NDBenzA $81 \%$, NPePicA $75 \%$, NNN $77 \%$, NNK $78 \%$, NAB/NAT $75 \%$.

Les paramètres influant sur les quantités de TSNA contenues dans le courant principal ont été examinés également. La formation d'artefact de TSNA pendant le piégeage du courant principal n'a pu être observée dans les conditions expérimentales standard. Il a été constaté que le volume des bouffées avait une forte incidence sur les quantités de TSNA qui deviennent plus élevées lorsqu'il augmente.

La méthode présentée permet d'obtenir des résultats reproductibles et fiables en un temps relativement réduit.

\section{INTRODUCTION}

Tobacco-specific nitrosamines [TSNA]* show the highest concentrations of any group of carcinogens in the mainstream smoke of cigarettes (1) and the highest concentrations of carcinogenic nitrosamines reported in other consumer products (2). Two of the known TSNA, N'-nitrosonornicotine [NNN] and 4-(methylnitrosamino)-1-(3-pyridyl)-1-butanone [NNK], are powerful carcinogens which induce cancer in the nasal cavity, oesophagus, lung and liver of laboratory animals (3).

For a research program on TSNA in the mainstream smoke of a representative number of European cigarettes (4) a practicable method for their determination was needed. Other authors (5-9) have previously reported on TSNA determinations in the mainstream smoke of cigarettes. They all used the sampling and rather time-consuming clean-up procedure of HECHT et al. (5). All authors with the exception of ARRENDale et al. and Kuus and KuHN $(9,6)$ used ${ }^{14} \mathrm{C}-\mathrm{NNN}$ as the internal standard. It was important for us to use an internal standard which can be detected by the same method as the TSNA. It should have a recovery rate and chromatographic properties similar to those of the TSNA. Another important point was to have a less time-consuming clean-up procedure. The method of HECHT et al. was modified for our purposes.

To test the reliability and reproducibility of the results, parameters influencing the TSNA values such as artifact formation, puff volume and puff profile had to be investigated.

\section{MATERIALS AND METHODS}

\section{Apparatus}

For the analysis of the mainstream smoke of cigarettes a modified 30-port smoking machine with a rotating head (Type Hamburg II, Heinr. Borgwaldt, Hamburg, Federal Republic of Germany) was used. According to Horfmann et al. $(10,11)$ cigarettes were only put in every second port. Every other port was connected to a nitrogen source. In between the smoking intervals nitrogen was automatically flushed through the smoking head by means of a magnetic valve device to displace the smoke remaining within the connection to the wash bottles. This was done to prevent artifactual TSNA formation. The mainstream smoke was passed through 3 gas wash-bottles containing a total of $250 \mathrm{ml}$ citratephosphate buffer ( $\mathrm{pH} \mathrm{4.5)}$ and $20 \mathrm{~mm}$ ascorbic acid (5),

\footnotetext{
* The abbreviations osed and the chemical substance prime names according to Chemical Aastracts in square brackets are: TSNA for tobacco-specific nitrosamines, NNN for $N^{\prime}$-njtrosonornicotine [3-(1-nitroso-2-pyrrolidinyl)pyridine], NNX for 4-(methylnitrosamino)-1-(3-pyridyl)-1-butanose, NAB for $N^{2}$-nitrosoanabasine [3-(1-nitroso-2-piperidinyl)-pyridine], NAT for $N^{\text {: }}$ nitrosoanatabine $[1,2,3,6$ - tetrahydro-1-nitroso-2,3-bipyridine $]$, NDBenzA for $N$-nitrosodibenzylamine, NPePieA for $N^{\prime}$-nitrosopentylpicolylamine, TEA for thermal energy analyzer, GC for gas chromatography.
} 
Figure 1.

Smoking device for the analysis of tobacco-speciflc nitrosamines [TSNA] in mainstream smoke.

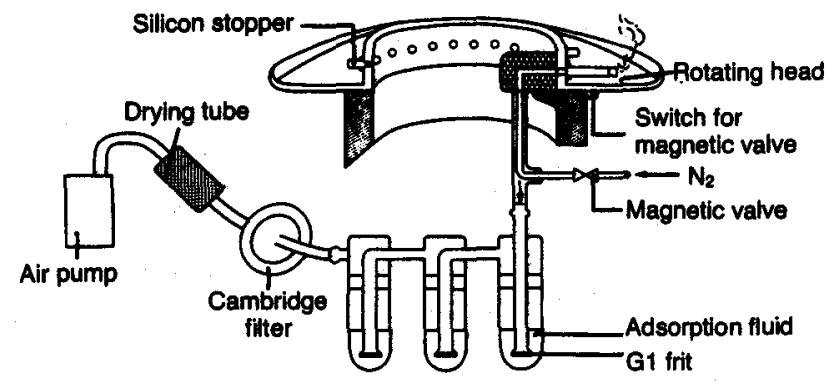

followed by a $92 \mathrm{~mm}$ Cambridge filter and a continuously working pump (Figure 1$)$. NPePicA (1 $\mathrm{kg}$ in $1 \mathrm{ml}$ ethanol) and/or NDBenzA ( $1 \mu \mathrm{g}$ in $1 \mathrm{ml}$ ethanol) were added to the first wash bottle as internal standards.

For the investigations into the nitrosation potential of freshly generated mainstream smoke the following solvents were used: $2 \mathrm{M} \mathrm{NaOH}(6)$, water, cyclohexane, citrate-phosphate buffer containing ascorbic acid (5). In some experiments the order of the adsorption traps was reversed, i.e. the smoke was first passed through the Cambridge filter and then through the wash bottles.

For some comparative analyses a single-port smoking machine with a piston pump (Type RM 1/G, Heinr. Borgwaldt) and a $44 \mathrm{~mm}$ silicon-bound glass-fibre filter for smoke collection was used.

The determination of the puff profile was carried out using a differential pressure monitor (PD 3V, Hottinger Baldwin Messtechnik, Darmstadt, Federal Republic of Germany). The puff volume was measured with a bubble flow meter (Heinr. Borgwaldt, Hamburg). GC analyses were performed on a Hewlett-Packard Model 5880A gas chromatograph directly connected to a thermal energy analyzer (TEA 502, Thermo Electron Corporation, Waltham, Massachusetts, U.S.A.) as a detector with a modified pyrolyzer. A CTR filter (Thermo Electron Corporation) was used to trap organic material after pyrolysis.

\section{Cigarettes}

The method was developed using standard cigarettes (C 20) which were generously donated by Reemtsma Cigarettenfabriken GmbH, Hamburg, Federal Republic of Germany. The cigarette can be characterized by the following parameters: length $84 \mathrm{~mm}$, tobacco weight approx. $790 \mathrm{mg} /$ cigarette, ventilation $16 \%$, moisture $14.0 \%$, total alkaloids $1.63 \%$, nicotine $1.50 \%$, nornicotine $0.12 \%$, anabasine/myosmine $0.007 \%$, anatabine $0.05 \%$, nitrate nitrogen $0.14 \%$, tar delivvery $13.7 \mathrm{mg} /$ cigarette, smoke nicotine $0.99 \mathrm{mg} /$ cigarette, nitrogen oxide $0.12 \mathrm{mg} /$ cigarette (12). For reference analyses a commercial American-blend filter ciga- rette (smoke deliveries: tar $13 \mathrm{mg} /$ cigarette, nicotine $0.9 \mathrm{mg} /$ cigarette) and a non-filter blend cigarette (smoke deliveries: tar $20 \mathrm{mg}$ / cigarette, nicotine $1.2 \mathrm{mg}$ / cigarette) purchased in the Federal Republic of Germany in 1987 were also taken.

Prior to smoking, the cigarettes were kept in a chamber of $60 \pm 3 \%$ relative humidity and $22 \pm 2{ }^{\circ} \mathrm{C}$ for at least $24 \mathrm{~h}$ according to the German standard DIN 10244 (13). For practical reasons a $24.66 \% \mathrm{NaOH}$ solution was preferred to adjust the relative humidity instead of a saturated $\mathrm{NaBr}$ solution.

\section{Smoking Conditions}

For each analysis, 15 cigarettes were smoked under standard smoking conditions with $1 \mathrm{puff} / \mathrm{min}$ of $35 \mathrm{ml}$ volume and $2 \mathrm{~s}$ duration. The non-filter cigarettes were smoked to a butt length of $23 \mathrm{~mm}$; the filter cigarettes were smoked to the length of the filter plus $8 \mathrm{~mm}$, and filter overwrap plus $3 \mathrm{~mm}$, respectively, as required by International Standard ISO 3308 (14).

The 30-port smoking machine with the continuously working pump did not generate a bell-shaped puff profile as is required by ISO 3308. A "half bell-shaped" profile was obtained when the wash bottles and the Cambridge filter were used. A bell-shaped profile was achieved with the single-port smoking machine with piston pump.

\section{Reagents}

NNK was a generous gift from Dr. D. Hoffmann, Naylor Dana Institute for Disease Prevention, American Health Foundation, Valhalla, New York, U.S.A., and was also obtained from Chemsyn Science Laboratories, Lenexa, Kansas, U.S.A. NDBenzA, NNN and NAB were synthesized by methods reported in the literature (15-17). The purity was $>99 \%$. NPePicA was synthesized as previously reported (18); purity was $98 \%$. Nicotine and nornicotine were purchased from Roth, Karlsruhe, Federal Republic of Germany.

All the reagents used were of analytical grade.

\section{GC Determination of TSNA}

The injection-port temperature was $260^{\circ} \mathrm{C}$ and the helium carrier gas flow was $30 \mathrm{ml} / \mathrm{min}$. GC analyses were performed on a glass column $(2.4 \mathrm{~m} \times 2 \mathrm{~mm}$ inside diameter) packed with $10 \%$ OV 17 on Chromosorb WHP (80/100 mesh). The GC oven temperature was programmed using a profile starting at $180^{\circ} \mathrm{C}$ with $3 \%$ min to $230^{\circ} \mathrm{C}$, held at $230^{\circ} \mathrm{C}$ for 5 minutes. The GC column was directly connected to the heated interface $\left(300^{\circ} \mathrm{C}\right)$ of the TEA detector's modified pyrolyzer $\left(500^{\circ} \mathrm{C}\right)$. All nitrosamines with the exception of NAB and NAT were baseline separated. Results were calculated by peak area comparison with the aid of an elec- 
tronic integration system (Trilab 2000, SES, NiederOlm, Federal Republic of Germany) using an internal standard method. NPePicA and/or NDBenzA were used as internal standards. NAB and NAT were calculated as a group.

\section{Mainstream Smoke Analysis for TSNA}

\section{A. 30-Port Smoking Machine}

The filter and the trapping fluid were cleaned up and analyzed individually.

1. Analysis of the Cambridge Filter: The filter was extracted three times with dichloromethane to a total volume of $350 \mathrm{ml}$. NPePicA (1 $\mu \mathrm{g}$ in $1 \mathrm{ml}$ ethanol) and/or NDBenzA ( $1 \mu \mathrm{g}$ in $1 \mathrm{ml}$ ethanol) were added to the combined dichloromethane extracts as internal standards. The extract was concentrated to $2 \mathrm{ml}$ using a rotary evaporator and chromatographed on $\mathbf{4 g}$ of basic alumina (activity II) on a $12 \mathrm{~cm} \times 50 \mathrm{~mm}$ column. The TSNA and internal standards were eluted with $4 \mathrm{ml}$ dichloromethane and $6 \mathrm{ml}$ of a dichloromethane:methanol $(10: 1(\mathrm{v} / \mathrm{v}))$ mixture. The eluate was washed once with $7.5 \mathrm{ml}$ citrate-phosphate buffer ( $\mathrm{pH} 4.5$ ) containing $20 \mathrm{~mm}$ ascorbic acid. This was necessary to remove nicotine from the extract. Nicotine disturbed the GC determination of the TSNA by reducing the detector response. For the re-extraction of the TSNA the buffer solution was extracted once with $2.5 \mathrm{ml}$ dichloromethane and once with $2.5 \mathrm{ml}$ of a dichloromethane:methanol $(10: 1(\mathrm{v} / \mathrm{v}))$ mixture. The three organic phases were combined, dried $\left(\mathrm{Na}_{2} \mathrm{SO}_{4}\right)$, concentrated to $2 \mathrm{ml}$ under a stream of nitrogen and analyzed by GC/TEA.

2. Analysis of the Trapping Fluid: The liquids from the traps were combined and extracted 3 times with $150 \mathrm{ml}$ dichloromethane. The combined dichloromethane extracts were dried over $\mathrm{Na}_{2} \mathrm{SO}_{4}$, concentrated to $2 \mathrm{ml}$ using a rotary evaporator and chromatographed on $4 \mathrm{~g}$ of basic alumina as described above. The additional washing procedure to remove nicotine was only necessary in cases where non-acidic liquids were used for smoke trapping. The eluate was concentrated to $2 \mathrm{ml}$ under a nitrogen stream and analyzed by GC/TEA.

\section{B. Single-Port Smoking Machine}

Ten cigarettes were directly smoked in sequence onto the same $44 \mathrm{~mm}$ silicon-bound glass-fibre filter. The filter was extracted with dichloromethane, $2 \mu \mathrm{g}$ NDBenzA in $2 \mathrm{ml}$ ethanol were added and the further clean-up was performed as described under A1. The final volume was $4 \mathrm{ml}$.

Figure 2.

GC/TEA chromatograms using $10 \%$ OV 17 on Chromosorb WHP as stationary phase. A: standard mixture of $N$ '-nitrosopentylpicolylamine [NPePicA], $N$ '-nitrosonornicotine [NNN], $N$ 'nitrosoanabasine [NAB], $N$-nitrosodibenzylamine [NDBenzA] and 4-(methylnitrosamino)-1-(3-pyridyl)-1-butanone [NNK] with $0.5 \mu \mathrm{g} / \mathrm{ml}$ for each nitrosamine; B: extract of the buffer solution (non-filter blend cigarette).
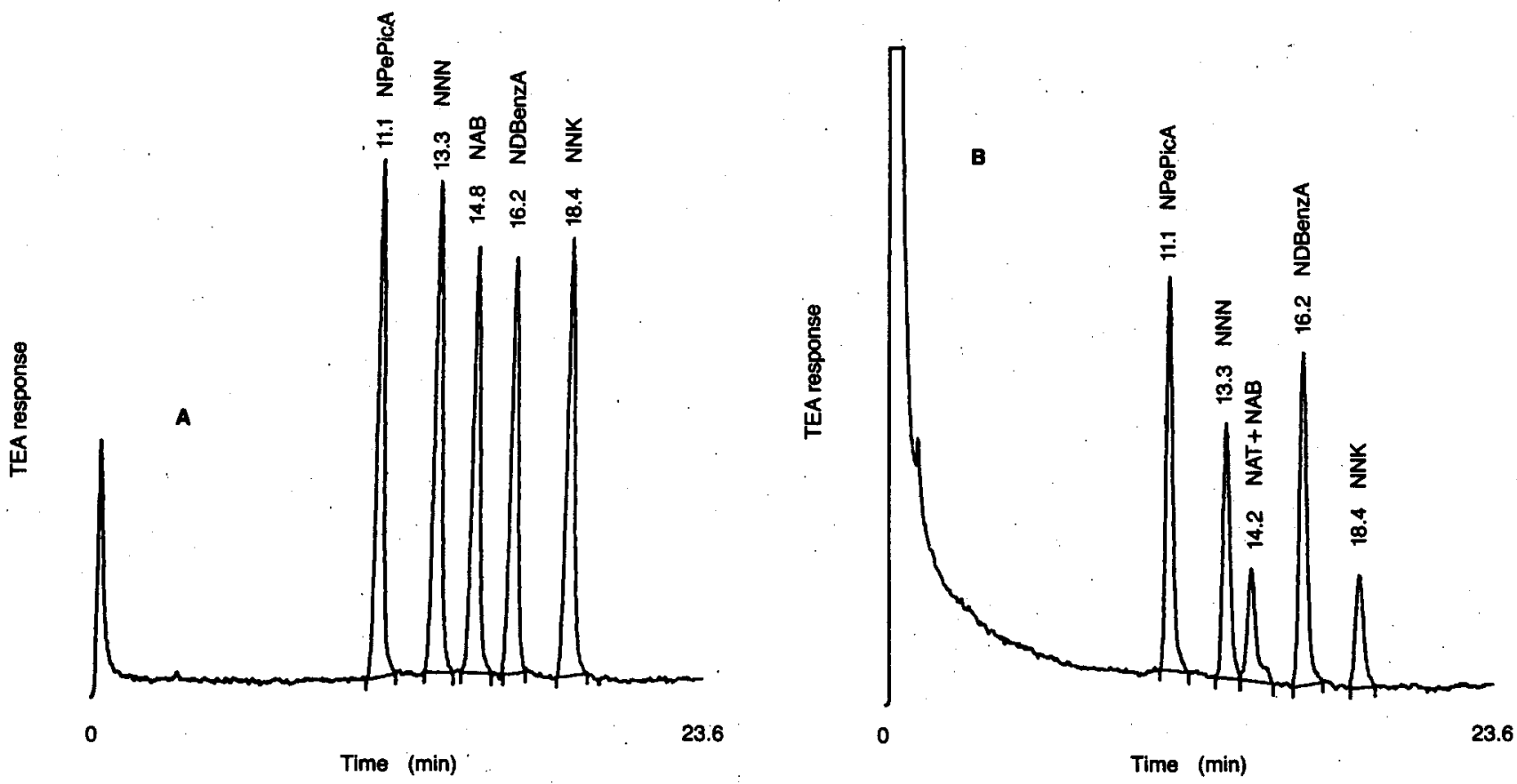
Table 1.

\section{Internal Standard}

The use of any internal standard for the determination of TSNA, which themselves have different physicochemical properties such as different extraction behaviour of NNN and NNK at different $\mathrm{pH}(18)$, always represents a compromise. Non-labelled internal standards, $N^{\prime}$-nitrosopentylpicolylamine (NPePicA), which has a similar structure to the TSNA, and $N$-nitrosodibenzylamine (NDBenzA), were used. In the literature ${ }^{14} \mathrm{C}-\mathrm{NNN}$ is described as internal standard $(5-8)$. Our aim, however, was to determine the recovery of the internal standard using the same detection method as for the TSNA. NDBenzA and NPePicA have gas chromatographic properties similar to the TSNA. Using OV 17 as stationary phase, NPePicA was eluted before NNN. The retention time of NDBenzA was between those of NAB/NAT and NNK, as is shown in Figure 2. With the method described, the recoveries of NPePicA and NDBenzA were similar to those of the TSNA; both were therefore useful internal standards.

\section{Clean-up Procedure}

Depending on the cigarette brand and the temperature of the buffer solution, the distribution of the TSNA between the buffer solution and the Cambridge filter varied widely. Between $7 \%$ and $50 \%$ were found on the Cambridge filter. No experiment achieved complete trapping of TSNA in the buffer solution. Buffer solution and Cambridge filter were separately extracted with dichloromethane. Since two different extractions (extraction of TSNA from buffer and from Cambridge filter) were used in the method, it was necessary to add internal standard to each extract. The recovery rates were different for filter and buffer solution. An individual internal standardization compensated for these differences and enabled us to get reproducible and accurate results.

For gas chromatography in combination with chemiluminescence detection a further clean-up procedure was necessary. The extraction of the TSNA from the buffer solution and the filter was followed by column chromatography on basic alumina. Using short columns with $4 \mathrm{~g}$ of basic alumina and $10 \mathrm{ml}$ of eluent sufficiently clean eluates were obtained. Owing to the extraction at $\mathrm{pH} 4.5$, the extracts of the buffer solution were free of nicotine whereas the filter extracts contained considerable amounts of nicotine. But nicotine interfered with GC/TEA determination and had therefore to be removed. This was done after column chromatography by washing the eluate with citrate-phosphate buffer containing $20 \mathrm{~mm}$ ascorbic acid. This buffer solution was re-extracted with dichloromethane and dichloromethane/methanol to improve the recovery.

With sufficiently clean samples the whole clean-up procedure can be done in less than half an hour.
Artfact formation of NNN after addition of $15 \mathrm{mg}$ nornicotine to different solvents In the traps when 15 standard cigarettes were smoked on a smoking machine.

\begin{tabular}{l|c}
\hline \multicolumn{1}{c|}{ Solvent } & $\begin{array}{c}\text { NNN } \\
\text { (ng/cigarette) }\end{array}$ \\
\hline $\begin{array}{l}\text { Citrate-phosphate buffer + ascorbic acid } \\
\text { without addition of nornicotine }\end{array}$ & 99 \\
\hline Cyclohexane & 259 \\
$2 \mathrm{M} \mathrm{NaOH}$ & 142 \\
Citrate-phosphate buffer + ascorbic acid & 103 \\
$\mathrm{H}_{2} \mathrm{O}$ & 130 \\
$\begin{array}{l}\text { Cambridge filter followed by wash bottles } \\
\text { (filter was fortified with 15 mg nornicotine } \\
\text { and the order of the adsorption traps was } \\
\text { reversed) }\end{array}$ & 204 \\
\hline
\end{tabular}

\section{Artifact Formation}

The nitrosation potential of freshly generated mainstream cigarette smoke was determined in different solvents using tobacco alkaloids as precursor amines. The secondary amine nornicotine was added to the solvents in the wash bottles in amounts of $1 \mathrm{mg}$ per cigarette smoked (i.e. $15 \mathrm{mg}$ in the trapping fluid) - the same amount as the total alkaloid concentration in the mainstream smoke of the test cigarette. Depending on the trapping fluid, nitrosation of nornicotine could be observed (Table 1). In citrate-phosphate buffer with ascorbic acid no nitrosation to NNN was detectable. In water and alkaline solution an increase in NNN was observed, which amounted to about $30 \%$ and $40 \%$ respectively, whereas a more than $100 \%$ increase in NNN was detected in cyclohexane. The nornicotine content of tobacco can vary widely but normally cigarette tobacco does not contain more than $10 \%$ of the total alkaloid concentration as nornicotine $(12,19)$, i.e. not more than $0.1 \mathrm{mg}$ per standard cigarette smoked accounted for nornicotine in the mainstream smoke. These data indicate that in water and in $2 \mathrm{M} N \mathrm{NaOH}$ $3 \mathrm{ng} /$ cigarette NNN and $4 \mathrm{ng} /$ cigarette NNN respectively might be attributed to artifact formation. In cyclohexane $16 \mathrm{ng} /$ cigarette NNN would be formed as a result of artifact formation. Thus for the standard cigarette with $99 \mathrm{ng}$ of NNN per cigarette only about $16 \%$ of NNN could be attributed to artifact formation in cyclohexane. If $\mathrm{H}_{2} \mathrm{O}$ or $2 \mathrm{M} \mathrm{NaOH}$ were used for trapping, $3 \%$ to $4 \%$ of NNN would be due to artifact formation, which is within the range of standard deviation for the method. Therefore, artifactual formation of NNN from nornicotine virtually does not play an important role in TSNA analysis.

The major tobacco alkaloid nicotine, containing a tertiary amino group, was also investigated with regard to its possible artifactual formation. Wash bottles contain- 
ing cyclohexane were fortified with nicotine in amounts of $1 \mathrm{mg}$ and $10 \mathrm{mg}$ nicotine per cigarette smoked (i.e. $15 \mathrm{mg}$ and $150 \mathrm{mg}$ in the trapping fluid). No additional NNN or NNK were observed. Furthermore, no artifactual NNK formation was observed at elevated temperatures up to $60^{\circ} \mathrm{C}$.

When the order of the adsorption traps was reversed, i.e. when the smoke was first passed through the Cambridge filter and then through the gas wash-bottles, the TSNA values determined for the standard cigarettes were the same within the normal ranges of deviation as those obtained with citrate-phosphate buffer with $20 \mathrm{~mm}$ ascorbic acid. In this case, all the TSNA were found on the Cambridge filter.

Using the standard cigarette, artifactual formation of NNN or NNK from nicotine was not observed. Artifact formation of TSNA from secondary amines had no influence on the TSNA values in the mainstream smoke. The low nitrosation potential was not surprising since freshly generated tobacco smoke contains only nitric oxide and no nitrogen dioxide (20). But nitric oxide alone is not a nitrosating agent (21).

To exclude the probability of artifact formation under conditions which cannot be represented by the standard cigarette, it was decided to include citrate-phosphate buffer in the trapping procedure.

\section{Criteria for Reliability}

Chemiluminescence detection in combination with gas chromatography is highly specific for compounds producing NO upon pyrolysis. In all analyses only nitrosamine-related peaks were detected.

For optimal detector performance organic material eluting from the pyrolyzer has to be trapped and this was done with a filter device. Nitric oxide generated from nitrosamines in the pyrolyzer can pass through the device unaffected. In the presence of amines, however, trapping or adsorption of nitric oxide can occur which results in a decrease of the detector signal (22). When nicotine was present in the smoke extracts, the response of the TEA detector was drastically reduced. The reduction of the detector signal was the same for

\section{Table 2.}

Recovery rates of TSNA, NDBenzA and NPePICA (1 $\mu \mathrm{g}$ of each nitrosamine was added to the buffer solution and the Cambridge filter).

\begin{tabular}{lc|c} 
& \multicolumn{2}{c}{ Percentage recovery rates } \\
\cline { 2 - 3 } & buffer solution & Cambridge filter \\
\hline NDBenzA & 89 & 81 \\
NPePicA & 83 & 75 \\
NNN & 85 & 77 \\
NNK & 88 & 78 \\
NAB/NAT & 85 & 75 \\
\hline
\end{tabular}

all the TSNA and the internal standard. To improve the sensitivity of the method and to avoid interference with amines, nicotine had to be removed in the course of analysis.

The GC parameters were optimized for NNN and NNK. Under these conditions NAB and NAT could not be separated. Optimum conditions for resolving NAB and NAT resulted in a broadening of the NNK peak and increased run times. Since our interest was mainly focused on the fast and reliable determination of NNN and NNK, the nitrosamines NAB and NAT were calculated as a group. For these reasons a $2.4 \mathrm{~m}$ glass column packed with $10 \%$ OV 17 on Chromosorb WHP was chosen and proved to be satisfactory especially for NNN and NNK.

The overall recovery of the method was calculated using NDBenzA as internal standard. Our aim was to utilize an internal standard which has physicochemical properties that are close to those of the TSNA. Among several pyridine-derived nitrosamines, NPePicA proved to be an ideal internal standard for TSNA analysis. To prove the suitability of NPePicA and NDBenzA as internal standards, a recovery study under smoking conditions was performed. One half of the filter was spiked before smoking and one half of the buffer solution was spiked after smoking with $1 \mu \mathrm{g}$ of each of the following: NNN, NNK, NAB, NDBenzA and NPePicA. The other parts of filter and buffer solution were spiked with $1 \mu \mathrm{g}$ of each internal standard. For the calculation the TSNA concentration which was originally present in the mainstream smoke was subtracted from the TSNA concentration obtained after spiking. This difference was compared to the nitrosamine concentration used for spiking and the resulting recoveries were determined (Table 2). For the buffer solution the recoveries were as follows: NDBenzA $89 \%$, NNN $85 \%$, NNK $88 \%$, NAB/NAT $85 \%$, NPePicA $83 \%$. For the

Figure 3.

Dlagrammatic representation of the "half bell-shaped" puff protlle.

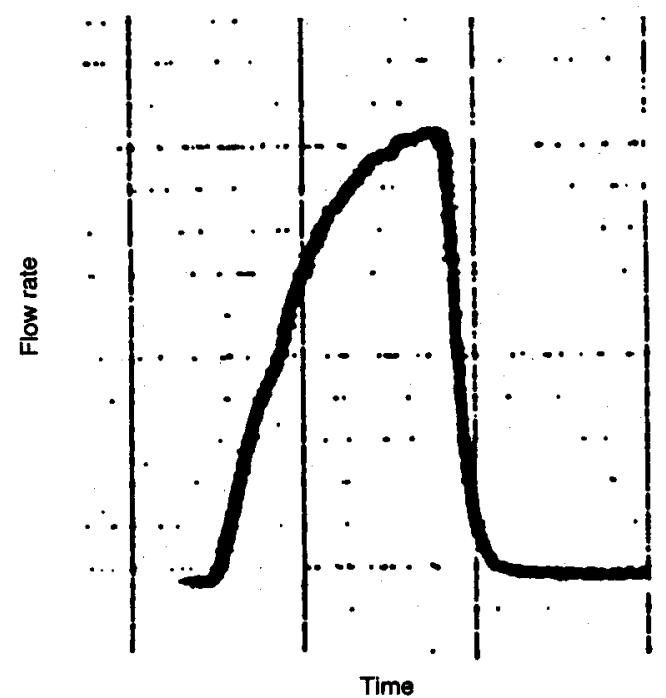


filter the following recovery rates were determined: NDBenzA $81 \%$, NNN 77\%, NNK 78\%, NAB/NAT $75 \%, \mathrm{NPePicA} 75 \%$. These results show that the recovery rates of the individual TSNA are comparable with the recoveries of NPePicA and NDBenzA. This allows an accurate correction for losses in the course of analysis using NDBenzA or NPePicA as internal standard. However, it was occasionally observed that NDBenzA was recovered at a much lower rate than NPePicA and the TSNA. Calculating the TSNA on NPePicA as the internal standard resulted in more accurate values. NDBenzA was suitable only if its recovery was at least $60 \%$. Analyses with a lower recovery had to be repeated or calculated based on NPePicA.

The minimum detection limit for NNN, NNK and $\mathrm{NAB} / \mathrm{NAT}$ respectively was $4 \mathrm{ng} /$ cigarette with a GC/TEA detection limit of $0.15-0.25 \mathrm{ng} /$ injection. The mean value of 5 analyses in the mainstream smoke of a filter cigarette was $69 \pm 11 \mathrm{ng} /$ cigarette for NNN, $42 \pm 4 \mathrm{ng} /$ cigarette for NNK and $68 \pm 9 \mathrm{ng} /$ cigarette for the sum of NAB and NAT.* Since no artifactual formation of NNK and only negligible artifactual formation of NNN was observed, the actual TSNA concentration in mainstream smoke was determined.

Considering that cigarette tobacco is not completely homogeneous the data shown account for good reproducibility and reliable results.

\section{Influence of Puff Profile}

The standard cigarette and a consumer filter cigarette were smoked with different puff profiles: bell-shaped profile and "half bell-shaped" profile (Figure 3). The other smoking parameters were held constant. The results obtained with the bell-shaped profile and the "half bell-shaped" profile were the same within the normal ranges of deviation (Table 3 ).

Thus the "half bell-shaped" profile did not influence the TSNA delivery in mainstream smoke.

\section{Influence of Puff Volume}

A first application of this method was to investigate the influence of the puff volume. For this purpose only two cigarette types were chosen, the standard cigarette (C20) and 2 non-filter German blend cigarette. Both brands were smoked with different puff volumes. The other smoking conditions were held constant. For all TSNA the mainstream smoke values increased with increasing puff volume (Figure 4). For these two cigarette types the relationship was linear. It should be pointed out that these two examples cannot be generalized. Publication of a more detailed study on parameters in-

\footnotetext{
* For the repeatability study a different batch of C 20 cigarettes had to be used which showed a significant difference in TSNA amounts in mainstream smoke.
}

Table 3.

TSNA values of two different brends smoked whth a different puff profile.

\begin{tabular}{c|c|c}
\hline $\begin{array}{c}\text { NNN } \\
\text { (ng/cigarette) }\end{array}$ & $\begin{array}{c}\text { NNK } \\
\text { (ng/cigarette) }\end{array}$ & $\begin{array}{c}\text { NAB + NAT } \\
\text { (ng/cigarette) }\end{array}$ \\
\hline
\end{tabular}

\section{Test clgarettes}

"half bell-shaped" profile

$\begin{array}{rrr}99 & 56 & 107 \\ 85 & 61 & 99\end{array}$

American-blend filter clgarettes

"half bell-shaped"

\begin{tabular}{lllll} 
profile & 179 & 142 & 259 \\
bell-shaped profile & 215 & 145 & 285 \\
\hline
\end{tabular}

fluencing the TSNA yield in mainstream smoke is in preparation.

\section{CONCLUSIONS}

The method reported is suitable for determining TSNA in the mainstream smoke of cigarettes. We consider it to be an improvement over other methods reported in

Figure 4.

TSNA values as a function of puff volume (A: standard cigarette, B: non-filter blend cigarette).
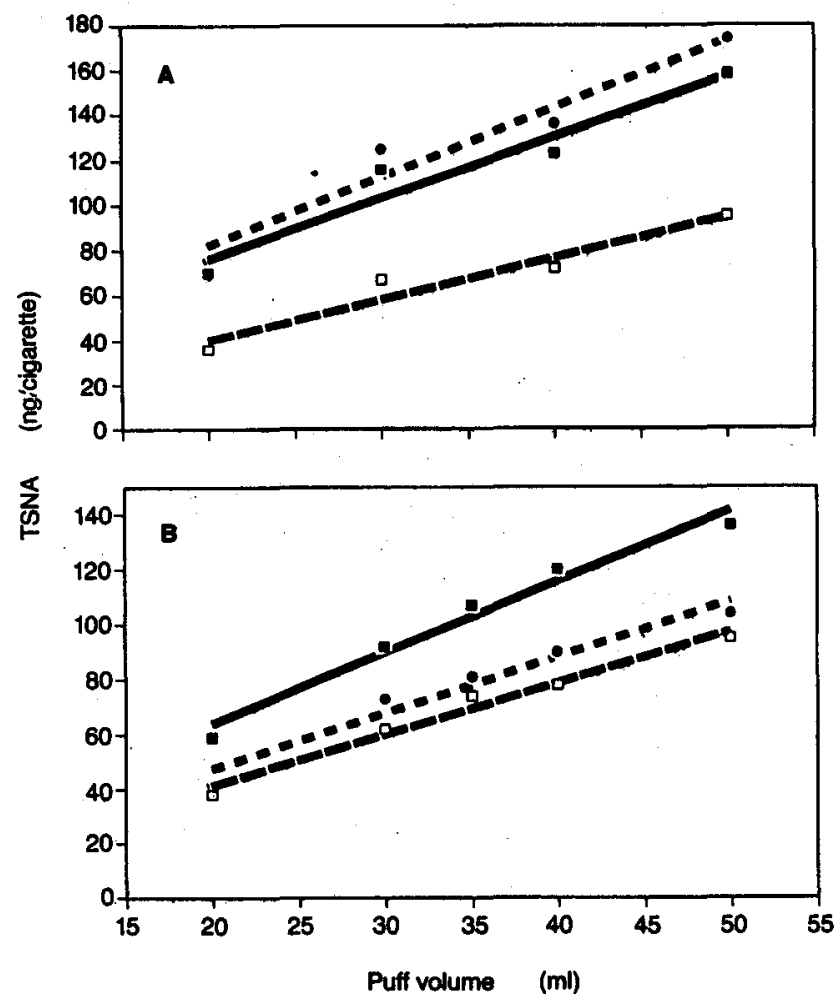

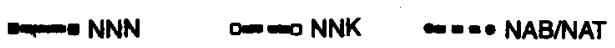


the literature because NDBenzA and NPePicA are used as internal standards. The recovery rates of NDBenzA and $\mathrm{NPePicA}$ are determined by the same detection method as the TSNA. The method accounts for gdod reproducibility and high sensitivity (detection limit: $0.15-0.25 \mathrm{ng} /$ injection, determination limit: $4 \mathrm{ng} /$ cigarette for NNN, NNK and NAB/NAT respectively). Another advantage of the method lies in the less time-consuming clean-up procedure. As the entire clean-up procedure can be carried out in a shorter time than that of HecHr et al. (5), more analyses can be performed in the same time.

\section{REFERENCES}

1. Hoffmann, D., J. D. Adams, K. D. Brunnemann, A. Rivenson and S. S. Hecht: Tobacco specific $\mathrm{N}$-nitrosamines - Occurrence and bioassays; in $N$-Nitroso compounds - Occurrence and biological effects, edited by $\mathrm{H}$. Bartsch, I. K. O'Neill, $M$. Castegnaro and M. Okada, International Agency for Research on Cancer, Lyon, IARC Sci. Publ. No. 41, 1982, pp. 309-318.

2. Hoffmann, D., S. S. Hecht, A. A. Melikian, N. J. Haley, K. D. Brunnemann, J. D. Adams and E. L. Wynder: Tumorigenic agents in tobacco products and their uptake by chewers, smokers, and non-smokers; Biochem. Mol. Epidemiol. Cancer 1986, 191-204.

3. Hoffmann, D., and S. S. Hecht: Tobacco and tobacco smoke (Volatile and tobacco-specific nitrosamines - general aspects); in Environmental carcinogens - Selected methods of analysis, Vol. 6: $\mathrm{N}$-Nitroso compounds, edited by $\mathrm{H}$. Egan, R. Preussmann, I. K. O'Neill, G. Eisenbrand, B. Spiegelhalder, H. Bartsch, International Agency for Research on Cancer, Lyon, IARC Sci. Publ. No. 45, 1983, pp. 63-67.

4. Fischer, S., B. Spiegelhalder and R. Preussmann: Tobacco-specific nitrosamines in mainstream smoke of West German cigarettes - tar alone is not a sufficient index for the carcinogenic potential of cigarette smoke; Carcinogenesis 10 (1989) 169173.

5. Hecht, S. S., J. D. Adams and D. Hoffmann: Tobacco-specific nitrosamines in tobacco and tobacco smoke; in Environmental carcinogens Selected methods of analysis, Vol. 6: $\mathrm{N}$-Nitroso compounds, edited by $\mathrm{H}$. Egan, R. Preussmann, I. K. O'Neill, G. Eisenbrand, B. Spiegelhalder, H. Bartsch, International Agency for Research on Cancer, Lyon, IARC Sci. Publ. No. 45, 1983, pp. 93-101.

6. Klus, H., and $H$. Kuhn: Untersuchungen über die nichtflüchtigen $\mathrm{N}$-Nitrosamine der Tabakalkaloide; Fachl. Mitt. Austria Tabakwerke No. 16, 1975, 307-317.
7. Rühl, C., J. D. Adams and D. Hoffmann: Chemical studies on tobacco smoke, LXVI. Comparative assessment of volatile and tobacco-specific $N$-nitrosamines in the smoke of selected cigarettes from the U.S.A., West Germany and France; J. Anal. Toxicol. 4 (1980) 255-259.

8. Adams, J. D., K. J. O'Mara-Adams and D. Hoffmann: Toxic and carcinogenic agents in undiluted mainstream smoke and sidestream smoke of different types of cigarettes; Carcinogenesis 8 (1987) 729-731.

9. Arrendale, R. F., W. J. Chamberlain, O. T. Chortyk, J. L. Baker and M. G. Stephenson: Determination of tobacco-specific $\mathrm{N}$-nitrosamines by capillary gas chromatography / selected ion monitoring mass spectrometry; Anal. Chem. 58 (1986) 565568.

10. Hoffmann, D., S. S. Hecht, I. Schmeltz, K. D. Brunnemann and E. L. Wynder: Chemical studies on tobacco smoke, XLIV. New separation techniques for classes of smoke compounds; Recent Adv. Tob. Sci. 1 (1975) 97-122.

11. Hoffmann, D., K. D. Brunnemann and K. S. Webb: Volatile nitrosamines in tobacco and mainstream and sidestream smoke and indoor environments; in Environmental carcinogens - Selected methods of analysis, Vol. 6: $N$-Nitroso compounds, edited by H. Egan, R. Preussmann, I. K. O'Neill, G. Eisenbrand, B. Spiegelhalder, H. Bartsch, International Agency for Research on Cancer, Lyon, IARC Sci. Publ. No. 45 (1983) 69-83.

12. Data received from Forschungsgesellschaft Rauchen und Gesundheit, Hamburg, Federal Republic of Germany.

13. DIN Deutsches Institut für Normung e.V.: Untersuchung von Tabak und Tabakerzeugnissen $-\mathrm{Kli}$ mate zum Konditionieren und Prüfen; DIN 10244, December 1977.

14. International Organization for Standardization (ISO): Cigarettes - Routine analytical cigarettesmoking machine - Definitions and standard conditions; ISO 3308, December 1986.

15. Hu, M. W., W. E. Bondinell and D. Hoffmann: Chemical studies on tobacco smoke, XXIII. Synthesis of carbon-14 labelled myosmine, nornicotine and $N$ '-nitrosonornicotine; J. Labelled Compd. 10 (1974) $79 \ldots 88$.

16. Hecht, S. S., R. M. Ornaf and D. Hoffmann: Chemical studies on tobacco smoke, XXXIII. $N^{\prime}-\mathrm{Ni}$ trosonornicotine in tobacco - Analysis of possible contributing factors and biological implications; $\mathrm{J}$. Natl. Cancer Inst. 54 (1975) 1237-1244.

17. Druckrey, H., R. Preussmann, S. Ivankovic and D. Schmähl: Organotrope carcinogene Wirkungen bei 65 verschiedenen $N$-Nitroso-Verbindungen an BDRatten; Z. Krebsforsch. 69 (1967) 103-201.

18. Spiegelhalder, B., S. J. Kubacki and S. Fischer: A method for the determination of tobacco-specific nitrosamines (TSNA), nitrate and nitrite in tobacco 
leaves and processed tobacco; Beitr. Tabakforsch. Int. 14 (1989) 135-144.

19. Piade, J. J., and D. Hoffmann: Chemical studies on tobacco smoke, LXVII. Quantitative determination of alkaloids in tobacco by liquid chromatography; J. Liq. Chromatogr. 3 (1980) 1505-1515.

20. International Agency for Research on Cancer, Lyon: Tobacco smoking; in IARC Monographs on the Evaluation of the carcinogenic risk of chemicals to humans, Vol. 38, 1986, p. 95.

21. Rōper, H.: Chemie und Bildung von $N$-Nitrosoverbindungen; in Das Nitrosamin-Problem, edited by R. Preussmann, Verlag Chemie, Weinheim, 1983, pp. 189-211.

22. Webb, K. S., and T. A. Gough: Suppression of chemiluminescent detector response toward nitrosamines; J. Chrom. 177 (1979) 349-352.

\section{Acknowledgement}

The authors wish to thank Dr. D. Hoffmann and Dr. K. Brunnemann, Naylor Dana Institute for Disease
Prevention, American Health Foundation, Valballa, New York, U.S.A., for helpful discussion. The authors are grateful to Prof. G. Grimmer and Dr. A. Glaser, Biochemisches Institut für Umweltcarcinogene, Großhansdorf, Federal Republic of Germany, for mainstream smoke collection with the single-port smoking machine. The authors wish to

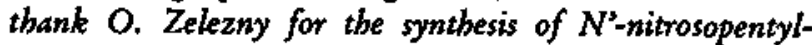
picolylamine. One of the authors (S.F.) is a recipient of a doctorate fellowship of the Friedrich-Ebert-Stiftung.

Authors'address:

Deutsches Krebsforscbungszentrum, Institut für Toxikologie und Chemotherapie, Im. Newenheimer Feld 280,

Postfach 101949,

D-6900 Heidelberg $l$. 